OCCASIONAL PIECE

\title{
East African running dominance revisited: a role for stereotype threat?
}

\section{J Baker, S Horton}

Br J Sports Med 2003;37:553-555

Regardless of the possible existence of physiological advantages in East African runners, belief that such differences exist creates a psychological atmosphere that can have significant consequences on performance. This is known as stereotype threat and can feature in many sports.

See end of article for authors' affiliations

......................

Correspondence to: Dr Baker, School of Physical and Health Education, Queen's University, Kingston K7L 3N6, Canada; jrb2@post.queensu.ca

Accepted2December 2002
$\mathrm{R}$ esearchers have long speculated on the factors that contribute to making an elite athlete. When a particular group appears to dominate a given domain, even more speculation and interest is generated. Current examples from sport include the American dominance of basketball and the Northern European dominance of Nordic skiing. An example that has garnered much attention ${ }^{12}$ is East African dominance of middle and long distance running. Although several empirically based positions have been advanced to explain the interindividual variation in performance, ${ }^{34}$ the dominance of black athletes in certain sports has been commonly attributed to factors such as social Darwinismthat is, the hardships of slavery resulted in a degree of genetic selection ${ }^{5}$ - and environmental determinism - that is, physiological adaptations associated with living under certain environmental conditions.

Hamilton $^{6}$ examined empirical evidence for a range of influences that may contribute to East African running dominance, including environmental, social, psychological, and physiological variables. After examining research from various disciplines, he concluded that there was no clear explanation for the East African supremacy. However, Hamilton argued that psychological factors may perpetuate this dominance by attributing differences between African and white running performances to stable external factors, thereby disempowering white runners and empowering East African runners. Regardless of the possible existence of physiological advantages in East African runners, belief that such differences exist creates a psychological atmosphere that can have significant consequences on performance.

\section{STEREOTYPE THREAT}

Recent research in psychology has unveiled insights that are particularly relevant to this debate. It is distinctly possible that what we believe to be true about our genetic make up may be more important than what is actually true

Stone et al $^{7}$ gave black and white students a laboratory golf task that ostensibly measured "natural athletic ability", "sport intelligence", or "sport psychology", depending on how the test was presented. Nothing changed in the test itself, just the perception of what the test measured. Both black and white students scored equally well on the sport psychology control condition. However, black participants outperformed white ones when the task was framed as a test of natural athletic ability, whereas white participants outperformed black ones when the task was framed as a test of sport intelligence. This phenomenon is referred to as stereotype threat and may be of help in explaining the dominance of certain sports by specific groups. Although scientific inquiry into genetic differences between races remains unresolved, previous research suggests that belief in such differences has a large impact on performance.

Steele and Aronson ${ }^{8}$ introduced stereotype threat as an explanation for the lower scores of black American students on standardised intelligence tests. The authors had been perplexed by the persistent gap in scores between blacks and whites, which endured even if black students came from well educated families of middle class standing. However, Steele and Aronson ${ }^{8}$ found that black students scored just as well as whites on standard intelligence tests when the tests were presented as diagnostic tools that did not measure intellectual capacities. They determined that it was not the test itself rather the situational pressure surrounding the test that resulted in poorer scores. Performance decreased when black students were confronted with the possibility of confirming a widespread stereotype about low intelligence in blacks.

Significantly, stereotype threat affects the academic vanguard more than it does the weaker students. A person has to care about a domain in order to be disturbed by the prospect of being stereotyped in it. Good students are generally invested in and have identified with the domain and thus are more prone to the situational pressure that is stereotype threat. Students who did not identify with the domain were remarkably unaffected. Weaker students reduced cognitive effort as soon as the test became challenging, resulting in poor performance, regardless of whether they were under stereotype threat or not. ${ }^{9}$ Therein lies another key to stereotype threat-the test must be challenging. It is only when one gets to a difficult section, and the possibility arises of confirming the negative stereotype, that sufficient stress arises to impair performance.

Oddly enough, a person does not even have to believe the stereotype to be affected by it. Awareness, even at a subconscious level, appears 
to be sufficient. For example, Levy ${ }^{10}$ primed seniors using subliminal messages and then gave them a memory test. Those who had been primed with negative words associated with old age, such as senile or forgetful, performed worse than seniors primed with positive words like wise and sage.

Spencer et $a l^{11}$ found that stereotype threat was equally applicable to women and maths skills. If women are reminded of the stereotype that they are inferior to men in mathematical ability, their test scores decrease. If the same test is reframed so that women believe it is simply a research tool, they score just as well as men. Current findings indicate that anywhere a stereotype exists, stereotype threat can be invoked and performance depressed. In a related study, white men, selected on the basis of their strong maths skills, performed worse when they were compared with Asian men, a group traditionally thought to excel at maths. A control group not subjected to stereotype threat suffered no such performance decrease. ${ }^{12}$

The sporting field also contains its share of stereotypes, particularly when it comes to black-white differences. The perception of the athletic superiority of black people is widespread, with the media contributing substantially to such thinking. ${ }^{25}$ Stone et $a l^{13}$ examined popular perceptions of racial stereotypes by having participants evaluate the abilities of a male basketball player based on a radio broadcast of a college game. Even though participants listened to the same broadcast, they were more likely to attribute talent and natural athletic ability to the player if they thought he was black and were more likely to attribute hard work and sport intelligence to the player if they believed he was white.

This widespread societal belief in the athletic superiority of blacks is actually a relatively recent phenomenon. Hoberman $^{14}$ notes that during colonial rule blacks were considered inferior sportsmen. In fact, at the dawn of the 20th century there was concern even among black scholars at the lack of physicality of the black race. ${ }^{14}$ However, the tables have turned considerably in the past hundred years. Impressive accomplishments from black athletes during the first decade of the 1900s-for example, Marshall Taylor and Jack Johnson-followed by the record breaking performances of black sprinters like Jesse Owens provided the basis for the belief that black athletic superiority is genetic in origin. ${ }^{15}$ The current dominance of black athletes in a number of high profile sports has certainly done nothing to dispel this belief. Furthermore, as Hamilton ${ }^{6}$ suggests, the psychological edge this belief gives black athletes may be the key to maintaining that superiority. Indeed, in stereotype threat we see evidence of the power of such beliefs.

\section{Short term effects}

The poorer performance associated with stereotype threat has been attributed to the anxiety and distress caused by association with a negative stereotype. Blascovich et al ${ }^{16}$ examined the effects of stereotype threat on blood pressure in African Americans. They found that groups placed under stereotype threat displayed larger increases in mean arterial blood pressure (a measure of somatic anxiety) and performed more poorly on difficult test items than African Americans not under stereotype threat. In typical models of anxiety ${ }^{17}$ (fig 1), the occurrence of a stressor, in this case stereotype threat, creates a state of anxiety. State anxiety ${ }^{18}$ is manifested either somatically through physical responses, such as sweating and increased respiration, or cognitively through worry or concentration disruption. Each of these manifestations has been linked to negative effects on physical performance. ${ }^{19}$ Further, whereas a certain amount of physical arousal has been seen as beneficial for sport performance (cf the inverted U hypothesis), ${ }^{20}$ certain research ${ }^{21}$ suggests that

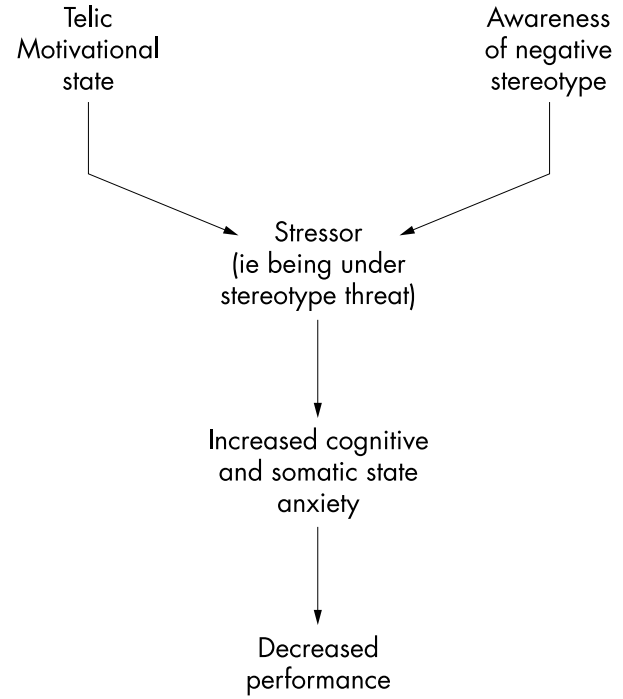

Figure 1 Proposed model of stereotype threat effects on sport performance.

any amount of cognitive anxiety is detrimental to performance.

Moreover, athletes performing at elite levels of competition normally adopt a telic, or serious, goal oriented motivational state. To the elite athlete, performing well is an important outcome. However, researchers ${ }^{22}{ }^{23}$ suggest that adopting a motivational state that is telic is more highly affected by anxiety than adopting a paratelic - that is, playful, nonserious-motivational state.

\section{Long term effects}

Perhaps the most damaging effects of stereotype threat are long term, such as feelings of dissatisfaction and ultimately dropout from sport. The benefits of long term involvement in physical activity are well known. They include increases in physical competence and associated increases in self esteem. ${ }^{24}$ However, Steele ${ }^{25}$ postulated that, in chronic situations of stereotype threat, individuals become pressured to "disidentify" with the domain to preserve feelings of self worth. Disidentification involves a reconceptualisation of one's self image to remove the value associated with a domain, thereby reducing the impact of negative performance. Stone ${ }^{26}$ recently replicated these results in a sport context.

Disidentification, although useful for maintaining self image, can undermine the motivation required for long term involvement in an activity. Sustained motivation is dependent on feelings of achievement and accomplishment. ${ }^{27}$ In a related study, Stone ${ }^{26}$ found that stereotype threat was related to the quality of practice performed by participants executing a golf task. Specifically, white athletes who felt they were being examined for natural athletic ability showed less practice effort than white athletes who were not under the threat of confirming racially based stereotypes-that is, poor white athleticism. In addition, stereotype threat only affected athletes for whom sport was an important component of their self concept. Participants who were disconnected from the outcome of the task performed at a level no different from control subjects. Stone hypothesised that athletes concerned with confirming a racially based stereotype "self handicap"- that is, perform less effortful practice-to create ambiguity about the cause of a poor performance. Athletes proactively respond to an anticipated mediocre outcome by withdrawing practice effort, thereby avoiding the confirmation of a stereotype about poor natural athletic ability in white athletes. Although longitudinal 
studies of the effects of these actions have not been performed, it seems reasonable that decreased practice effort over time would undermine skill acquisition and limit the physiological adaptations necessary for performance at the highest levels of sport competition.

The extent to which athletes choose or opt out of sports based on perceived genetic suitability is an area worthy of future study. Just as negative stereotypes can lead women away from maths based careers in finance or engineering, there is evidence to suggest that athletes may be choosing their sports based on athletic stereotypes. Coakley ${ }^{28}$ notes that young athletes have internalised these stereotypes and are choosing sport participation accordingly. He speculates that this is the reason why white running times in certain events have actually decreased over the past few years; whites are opting out of some sports based on perceived genetic inferiority.

\section{SUGGESTIONS FOR COACHES AND ATHLETES}

Coaches and support staff need to be aware of ways of dealing with situations involving stereotype threat. Steele ${ }^{25}$ presented methods for overcoming stereotype threat in academic settings, several of which are also useful for performance in the athletic environment. Steele ${ }^{9}$ theorised that underperformance appeared to be rooted less in self doubt than in social mistrust. Therefore niceness and reassurance on the part of the teachers was not enough. Steele $^{9}$ found that emphasising high standards was the key to gaining social trust. For criticism to be accepted across the racial divide in an academic setting, feedback had to be given with the emphasis on high standards, conveyed with the belief that the student could achieve those standards.

Although this research has yet to be replicated in an athletic domain, it provides clear guidance for coaches working in multiracial environments. When dealing with athletes, coaches should consistently emphasise high standards of performance for all, irrespective of race. Evidence suggests in order for stereotype threat to influence performance, the stereotype must be made salient in the particular context. Accordingly, coaches should avoid off hand comments or jokes suggesting, for example, "white men can't jump" or "blacks are better runners", especially before competition. In addition, coaches and trainers should show clear optimism in their athlete's abilities. All attempts should be made to increase the athlete's feelings of self efficacythat is, the athletes' beliefs in their abilities to accomplish desired courses of action-before competition. Moreover, these feelings must be reinforced after the event regardless of the results to ensure that stereotype threat has a limited role in future competitions. Clearly, coaches should also stress the equivocal research findings on race and athletic performance. One method of reducing the negative consequences associated with stereotype threat is by minimising the legitimacy of the stereotype. If athletes are educated as to the lack of consistent findings for racial dominance in sport, the power of the stereotype may be effectively limited.

Research examining the role of stereotype threat in elite levels of performance is virtually non-existent. As a result, the suggestions presented in this paper, although based on strong research with non-elite samples, remain speculative. Future research should consider the role of stereotype threat as a reason for performance differences in racially dominated sports such as middle and long distance running. Without indisputable evidence indicating the genetic advantages associated with a specific racial group, researchers should
Take home message

Athletes in sports that are dominated by specific racial groups should be cognisant of the effects that stereotypes have on performance. Coaches should make every effort to reduce or disarm potential stereotype "threats".

continue to examine alternative explanations for the apparent dominance of one group over another in sport.

\section{Authors' affiliations}

J Baker, S Horton, School of Physical and Health Education, Queen's University, Kingston K7L 3N6, Canada

\section{REFERENCES}

1 Bale J, Sang J. Kenyan running: movement culture, geography and global change. London: Frank Cass, 1996.

2 Entine J. Taboo: why black athletes dominate sports and why we're afraid to talk about it. New York: Public Affairs, 2000.

3 Bouchard C, Malina RM, Pérusse L. Genetics of fitness and physical performance. Champaign, IL: Human Kinetics, 1997.

4 Ericsson KA, Krampe RT, Tesch-Römer C. The role of deliberate practice in the acquisition of expert performance. Psychol Rev 1993; 100:363-406.

5 Kane M. An assessment of "Black is best." Sports Illustrated 1971;34:72-83.

6 Hamilton B. East African running dominance: what is behind it? Br J Sports Med 2000;34:391-4.

7 Stone J, Lynch Cl, Sjomeling $M$, et al. Stereotype threat effects on black and white athletic performance. J Pers Soc Psychol 1999;77:1213-27.

8 Steele CM, Aronson J. Stereotype threat and the intellectual test performance of african americans. J Pers Soc Psychol 1995;69:797-811.

9 Steele CM. Thin Ice: "Stereotype threat" and black college students. The Atlantic Monthly 1999;284:44-54.

10 Levy B. Improving memory in old age through implicit self-stereotyping. J Pers Soc Psychol 1996;71:1092-107.

11 Spencer SJ, Steele CM, Quinn DM. Stereotype threat and women's math performance. J Exp Soc Psychol 1999;35:4-28.

12 Aronson J, Lustina MJ, Good C, et al. When white men can't do math: necessary and sufficient factors in stereotype threat. J Exp Soc Psychol 1999;35:29-46.

13 Stone J, Perry ZW, Darley JM. "White men can't jump": evidence for the perceptual confirmation of racial stereotypes following a basketball game. Basic Appl Soc Psychol 1997; 19:291-306.

14 Hoberman J. Darwin's athletes: how sport has damaged America and preserved the myth of race. Boston: Houghton Mifflin, 1997.

15 Wiggins DK. "Great speed but little stamina": this historical debate over Black athletic superiority. In: Pope SW, ed. The new American sport history. Chicago, IL: University of Illinois Press, 1997:0312-38.

16 Blascovich J, Spencer SJ, Quinn D, et al. African Americans and high blood pressure: the role of stereotype threat. Psychol Sci 2001;12:225-9.

17 Spielberger CD. Stress and anxiety in sports. In: Hackfort D, Spielberger CD, eds. Anxiety in sports. New York: Hemisphere, 1989:3-17.

18 Spielberger CD. Theory and research on anxiety. In: Spielberger CD, ed. Anxiety and behavior. New York: Academic Press, 1966:1-17.

19 Smith RE, Smoll FL, Wiechman SA. Measurement of trait anxiety in sport. In: Duda JL, ed. Advances in sport and exercise psychology measurement. Morgantown, WV: Fitness Information Technology, 1998:105-27.

20 Gould D, Krane V. The arousal-athletic performance relationship: current status and future directions. In: Horn T, ed. Advances in sport psychology. Champaign, IL: Human Kinetics, 1992:119-41.

21 Wrisberg CA. The arousal-performance relationship. Quest 1994;46:60-77.

22 Kerr JH. Structural phenomenology and performance. Journal of Human Movement Studies 1987;13:211-29.

23 Martens R. Coach's guide to sport psychology. Champaign, IL: Human Kinetics, 1987

24 Fox KR. The physical self: from motivation to well being. Champaign, IL: Human Kinetics, 1997.

25 Steele CM. A threat in the air: how stereotypes shape intellectual identity and performance. Am Psychol 1997;52:613-29.

26 Stone J. Battling doubt by avoiding practice: the effects of stereotype threat on self-handicapping in White athletes. Pers Soc Psychol Bull 2003;in press.

27 Duda JL. Sport and exercise motivation: a goal perspective analysis. In: Roberts $G$, ed. Motivation in sport and exercise. Champaign, IL: Human Kinetics, 1992:57-91

28 Coakley J. Sport and society: issues and controversies, 7th ed. New York: McGraw-Hill, 2001. 